DOI: http://dx.doi.org/10.33846/hn31208

http://heanoti.com/index.php/hn

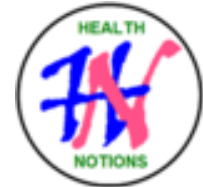

RESEARCH ARTICLE

URL of this article: http://heanoti.com/index.php/hn/article/view/hn31208

\title{
Relationship Between Risk Factors of Coronary Heart Disease on The Amount of
} Lesioned Coronary Artery

\begin{tabular}{c} 
Monitrya Nababan $^{1}$, Achmad Lefi $^{\mathbf{2}(\mathbf{C A})}$, Djohar Nuswantoro \\
\hline${ }^{\mathbf{3}}$ Faculty of Medicine, Universitas Airlangga, Indonesia; monitrya @ gmail.com \\
${ }^{2(\mathrm{CA})}$ Department of Cardiology and Vascular Medicine, Universitas Airlangga / Dr. Soetomo General Hospital \\
Surabaya, Indonesia; achmadlefi@ gmail.com \\
${ }^{3}$ Department of Public Health, Universitas Airlangga, Indonesia; djohar.nuswantoro@ gmail.com \\
\hline
\end{tabular}

\begin{abstract}
Objective: To determine the relationship of coronary heart disease traditional risk factors to the number of lesioned coronary arteries and calculate the relative risk. Methods: This study used an analytical research design with a retrospective cohort study design using patient catheterization report data. Data analysis was performed using the chi square test and relative risk in 449 individuals. Results: Based on the analysis results obtained $\mathrm{p}$ value $<0.05$ shows there is a relationship between risk factors for coronary heart disease with the number of coronary arteries that lesions based on age $(\mathrm{p}=0.013$ relative risk, 1,281; 95\% CI, 1,187 - 5,332), history of diabetes mellitus ( $\mathrm{p}=0.008 \mathrm{RR}, 1.98 ; 95 \%$ CI 1.192 - 3.287) dyslipidemia ( $\mathrm{p}=0.001 \mathrm{RR}, 2.5 ; 95 \%$ CI, 1.469 4.326) and a value of $\mathrm{p}>0.05$ indicating no relationship between risk factors for coronary heart disease with the number of coronary arteries the lesions based on sex, history of hypertension and history of smoking. Conclusion: There is a relationship between age, history of diabetes mellitus, history of dyslipidemia and the number of coronary arteries that are lesions in patients with coronary heart disease and there is no relationship between sex, history of hypertension and smoking history with the number of coronary arteries that are lesions in patients with coronary heart disease.
\end{abstract}

Keywords: single vessel disease; multivessel disease; coronary artery disease; risk factors CAD

\section{INTRODUCTION}

Vascular heart disease is the number one cause of death in developing countries, including Indonesia. In 2013, a total of 478,000 patients in Indonesia were diagnosed with coronary heart disease ${ }^{(1)}$. Coronary heart disease occurs due to narrowing of blood vessels in the heart muscle whose function is to drain oxygenated blood and nutrients to the heart muscle. Based on the Mosseri classification, this blockage is categorized as single vessel disease (SVD) and multiple vessel disease (MVD). Coronary heart disease with multiple arterial lesions is defined by the presence of stenosis with a diameter of $\geq 50 \%$ of two or more epicardial coronary arteries $^{(2)}$. Research shows that the prognosis of patients with coronary artery disease depends on the number of coronary arteries with lesions ${ }^{(3,4)}$. Subjects with multiple vessel disease (MVD) have a worse prognosis and higher mortality than subjects with single vessel disease (SVD). Revascularization in subjects with MVD can be achieved by percutaneous coronary intervention (PCI) or Coronary Artery Bypass Grafting (CABG) ${ }^{(3)}$.

To reduce the incidence of coronary heart disease, extensive research has been carried out on risk factors in both developed and developing countries. Some clinical practice guidelines recommend the use of risk of atherosclerotic cardiovascular disease (ASCVD) which is predicted to inform treatment initiation decisions. The American College of Cardiology / American Heart Association uses age, sex, systolic blood pressure, diabetes mellitus, smoking, and total lipoprotein and HDL cholesterol to estimate the risk of ASCVD ${ }^{(5)}$.

This study aims to analyze the relationship of risk factors for atherosclerotic cardiovascular disease, namely age, sex, smoking habits, history of diabetes mellitus, history of hypertension, and history of dyslipidemia to the number of coronary arteries in the lesion in patients undergoing percutaneous coronary intervention in Dr. Soetomo, Indonesia.

\section{METHODS}

This study was a retrospective cross-sectional study conducted at Dr. General Hospital Soetomo, Surabaya, Indonesia. Sampling used a total sampling technique from all patient catheterization reports that carried out percutaneous coronary intervention from January to December 2017. Patients with with non 
coronary heart disease were excluded in this study. Ethics Committee of the Regional General Hospital Dr. Soetomo Surabaya has approved this study.

\section{RESULTS}

From January 2017 to December 2017, 470 patients with suspected CHD were sent to carry out percutaneous coronary intervention, according to inclusion criteria, 449 patients were then divided into two groups namely multivessel $(n=360,80.2 \%)$ and single vessel $(n=89,19.8 \%)$.

Table 1. Distribution of single vessel disease and multivessel disease

\begin{tabular}{cccc}
\hline Variable & Mulitivessel $(\mathrm{n}=360)$ & Single-vessel $(\mathrm{n}=89)$ & $\mathrm{p}$-value \\
\hline Male & $296(82.2 \%)$ & $74(83.1 \%)$ & $<0.01$ \\
Female & $63(17.5 \%)$ & $15(16.9 \%)$ & \\
Age $\geq 45$ & $339(81.5 \%)$ & $77(83.1 \%)$ & $<0.01$ \\
Age $<45$ & $21(5.8 \%)$ & $12(13.5 \%)$ & \\
$\mathrm{BP}>140 / 90 \mathrm{mmHg}$ & $191(53.0 \%)$ & $43(48.3 \%)$ & $>0.05$ \\
$\mathrm{BP}<140 / 90 \mathrm{mmHg}$ & $169(56.3 \%)$ & $46(51.7 \%)$ & \\
FBG $\geq 126 \mathrm{mg} / \mathrm{dl}$ & $157(43.6 \%)$ & $25(28.1 \%)$ & $<0.01$ \\
FBG $<126 \mathrm{mg} / \mathrm{dl}$ & $203(56.4 \%)$ & $64(72.0 \%)$ & \\
Dyslipidemia & $152(42.2 \%)$ & $20(22.5 \%)$ & \\
Normolipidemia & $208(57.8 \%)$ & $69(77.5 \%)$ & \\
Smoking history & $219(60.8 \%)$ & $55(61.8 \%)$ & \\
No smoking history & $141(39.1 \%)$ & $34(38.2 \%)$ & \\
\hline
\end{tabular}

In the multivessel group, hypertension, diabetes and dyslipidemia were higher than those in the single group. Whereas male gender, age, and smoking habits did not have a statistically significant difference.

Table 2. Relationship and relative risk of risk factors to multivessel disease

\begin{tabular}{cccc}
\hline Variabel & RR & 95\% CI & p-value \\
\hline Sex & 0,991 & $0.88-1.12$ & 0.422 \\
Age & 1.281 & $1.19-5.33$ & 0.013 \\
Hypertension & 1.209 & $0.76-1.92$ & 0.422 \\
Diabetes mellitus & 1.980 & $1.19-3.29$ & 0.008 \\
Dyslipidemia & 2.521 & $1.47-4.33$ & 0.001 \\
Smoking history & 0.960 & $0.60-1.55$ & 0.867 \\
\hline
\end{tabular}

Analysis using the chi square test and relative risk calculator, age, diabetes mellitus, and dyslipidemia are important variables to distinguish patients with SVD from patients with MVD. These factors relatively multiply incidence of multivessel disease. While male sex, hypertension, and smoking habits are not significantly able to differentiate the number of lesioned coronary artery.

\section{DISCUSSION}

Atherosclerosis is a multifactorial disease of traditional risk factors for cardiovascular disease such as systemic hypertension, dyslipidemia, and others. The role of each variable continues to be studied, several studies show a greater or lesser influence of risk factors for coronary heart disease on the severity of the disease. Research also shows that diabetes mellitus, dyslipidemia, hypertension, sex and age manifest higher rates of multivessel disease while smoking in single vessel disease ${ }^{(6)}$.

Smoking is a strong predilection factor for the formation of plaques that are not calcified and are more susceptible. Marceloo et al's research shows that smoking relationship with plaque formation can lead to misinterpretation because smoking is a less correlative risk factor ${ }^{(7)}$. In this study, there was an insignificant value between the history of smoking and the incidence of multivessel disease in patients with coronary heart disease. This is also supported by other studies that show that the angiographic characteristics of plaque formation associated with smoking are more common among younger individuals ${ }^{(8)}$, because age is a broader predictor of disease and often carries other factors; hypertension, diabetes, and dyslipidemia. Angiographic studies in other studies have also shown that coronary artery abnormalities in smokers are comparable to nonsmokers ${ }^{(9)}$.

Dyslipidemia is one of the predictors of multivessel atherosclerotic event ${ }^{(7,10)}$ according to this study which shows the probability value of multivessel events is 2.5 -fold in dyslipidemic patients compared to the non-dyslipidemic group. Combined hyperlipidemia, simple hypercholesterolemia, MetS, and low HDL-c are associated with multivessel coronary artery disease independent of CVD risk factors and CAC score ${ }^{(11,12)}$. This is consistent with previous studies that stated that dyslipidemia was a significant risk factor for severe atherosclerotic disease, the average percentage of stenosis in the three main coronary arteries (LAD, RCA, and LCx) was significantly higher in the dyslipidemic age group than in the dyslipidemic age group nondilipidemic, 
especially in LAD and RCA. This is related to a very significant correlation between atherosclerotic lesions with HDL cholesterol, TC / HDL ratio and LDL / HDL ratio but other lipid fractions do not have a significant correlation $^{(10)}$. Low HDL levels correlate with the presence and severity of CAD. TC / HDL and LDL / HDL were higher in the multivessel group ${ }^{(13)}$ when compared to the single vessel disease group.

Diabetes increases the likelihood of multivessel disease ${ }^{(14)}$ especially in patients with kidney disease. Current research shows an increased risk of multivessel disease in diabetics by 1.98 (CI: 1.19-3.29) and also shows diabetes is an independent predictor factor of multivessel ${ }^{(7,15)}$ disease.Diabetes accelerates the progression of atherothrombosis with early onset of atherosclerosis compared with patients without diabetes ${ }^{(16,17)}$. Previous studies have shown an association between genetic scores consisting of 41 independent T2D risk variants and the severity of coronary heart disease regardless of disease status and lifestyle risk factors ${ }^{(18)}$.

Age is a strong independent factor in the presence of multivessel diseases ${ }^{(7,19)}$. The proportion of men with heart disease is significantly higher for all age groups but especially from ages 45-59 years ${ }^{(20)}$. In this study significant results were obtained between the age group $\geq 45$ years with the incidence of multivessel disease. This study shows an increased risk of multivessel disease in age group $\geq 45$ years by 1.28 (CI: $1.19-5.33$ ) This is not much different from other studies that mention among patients who are grouped by age, age group, patients in the $\geq 65$ years group have a higher risk of experiencing obstruction than the age group $<65^{(21)}$. Related to this, Monahan et al. explain the mechanism of decreased coronary vasodilation in older men. Worsening sympathetic control of coronary arteries plays a role in decreased myocardial blood supply in elderly men, especially in response to stress and activity. Old vessels show reduced medial VSMC counts, increased collagen deposition, and elastin lamellae fractures, which can cause vessel dilation and increased lumen size. To conclude, research by Monahan et al. further explained the age-related mechanism of coronary vasodilatation in older men. Worsening sympathetic control of coronary arteries plays a role in poorer myocardial blood supply in older men, especially in response to stress and activity ${ }^{(22)}$. Old vessels show a number of distinctive pathological processes, many of which are also seen in atherosclerosis. For example, older vessels show a reduction in the number of medial VSMCs, increased collagen deposition, and elastin lamellae fractures, which can cause vessel dilation. and an increase in lumen size ${ }^{(23)}$. Increased collagen and decreased elastin levels also occur with age. Besides that old age also causes impaired elasticity of blood vessels and hence increases blood vessels due to the stiffness blood vessels which subsequently causes hypertension ${ }^{(24,25)}$.

Male gender is often associated with the severity of coronary heart disease ${ }^{(25)}$, even other studies mention it as a strong predictor of the presence of multivessel disease ${ }^{(7)}$. Contradicting this research which states that male sex variable is one of the risk factors of multivessel disease. This is supported by previous studies that have evaluated sex differences in the total disease burden assessed anatomically and physiologically and the prognostic implications. The results of the study stated that although the percentage of diameter of angiographic stenosis was similar between men and women, the total physiological disease burden as assessed by fractional flow reserve (FFR) of the three blood vessels and SYNTAX functional score was lower in women. In addition, women showed lower MACE levels than $\operatorname{men}^{(26)}$. Some other studies also state that sex is not a predictor of multivessel disease $e^{(15,27,28)}$

Hypertension is a risk factor for ASCVD that has a strong influence on coronary heart disease, Lackland, et al. in a previous study observed for 8 years of follow-up, shows that preventing an increase in the average SBP and the incidence of hypertension in adolescents can reduce the average risk of coronary heart disease in 10 yeers prediction ${ }^{(29)}$. Compared with patients without hypertension, hypertensive patients have an increased incidence, extent, and severity of coronary atherosclerosis and tend to experience an increase in adverse cardiac events $^{(30)}$, nevertheless, in this study, an insignificant value was obtained between history of hypertension and the incidence of multivessel disease. This can be caused by the number of samples that lack or lack of detailed data on hypertension suffered by patients such as long history of hypertension and history of medication.

\section{CONCLUSION}

Multivessel coronary artery disease in RSUD Dr. Soetomo Indonesia, which was assessed by coronary angiography can be associated with age, dyslipidemia and diabetes but not with male sex, smoking history and hypertension. Age, dyslipidemia, and diabetes are significantly multiply the risk of multivessel disease.

\section{REFERENCES}

1. $\quad$ Kemenkes RI. Basic Health Research (Riset Kesehatan Dasar 2013). Jakarta: Kemenkes RI; 2018.

2. Alai MS, Rashid J, Kumar S, et al. Prevalence and characterization of coronary artery disease in patients with symptomatic bradyarrhythmias requiring pacemaker implantation. Indian Heart J. 2016;6-10.

3. Innocentiis C De, Zimarino M, Caterina R De. Coronary Is Complete Revascularisation Mandated for all Patients with Multivessel Coronary Artery Disease. Interv Cardiol 2018; 13:45-50.

4. Lopes NH, Paulitsch S, Gois F, et al. Impact of number of vessels disease on outcome of patients with stable coronary artery disease: 5-year follow-up of the Medical, Angioplasty, and bypass Surgery Study (MASS). Eur J Cardiothorac Surg. 2008;33:349-354. 
5. Rehan F, Qadeer A, Bashir I, et al. Risk Factors of Cardiovascular Disease in Developing Countries. Int Curr Pharm J. 2016;5:69-72.

6. Kastelein JJP, Duriez P. New Risk Factors for Atherosclerosis and Patient Risk Assessment. Circ. 2015;109:15-19.

7. José M, Cantarelli DC, José H, et al. Independent predictors of multivessel coronary artery disease: results from the Angiocardio Registry (Preditores independentes de doença arterial coronária multiarterial: resultados do Registro Angiocardio). Rev Bras Cardiol Invasiva. 2015;23:266-270.

8. Zhang WP, Yuan ZY, Liu Y, Jia L, Cheng H, Qi J, Wu H, Wang YN WD. Risk factors and coronary angiographic findings in young and elderly patients with acute myocardial infarction: a comparative analysis (青 年和老年急性心肌梗死患者危险因素及冠状动脉造影特点的对比分析). Nan Fang Yi to Da Xue Xue Bao. 2008;28:718.

9. Ms. JOR, Ebrahimi R, Lansky AJ, et al Impact of Cigarette Smoking on Extent of Coronary Artery Disease and Prognosis of Patients With Non-ST-Segment Elevation Acute Coronary Syndromes. JACC Cardiovascular Interventions. 2014;7:372-379.

10. Rabbani GM, Rahman A, Khan AR, et al.Role of Diabetic Dyslipidemia on Coronary Atherosclerotic Severity in Acute. Coronary Syndrome. Bangladesh Hear J. 2010;31:65-69.

11. Windecker S, Kolh P, Alfonso F, Collet JP, Cremer J, Falk V, Filippatos G, Hamm C, Head SJ, Jüni P, Kappetein AP, Kastrati A, Knuuti J, Landmesser U, Laufer G, Neumann FJ, Richter DJ, Schauerte P, Sousa Uva M, Stefanini GG. Tag WA 2014 ESC / EACTS Guidelines on myocardial revascularization: The Task Force on Myocardial Revascularization of the European Society of Cardiology (ESC) and the European Association for Cardio-Thoracic Surgery (EACTS) Developed with the special contribution o. Eur Hear J. 2014;135:2541-619.

12. Fihn SD, Blankenship JC, Alexander KP et al. 2014 ACC / AHA / AATS / PCNA / SCAI / STS focused updates of the guidelines for the diagnosis and management of patients with stable ischemic heart disease: a report from the American College of Cardiology / American Heart Association Task Force on Practice Guidelines. J Am Coll Cardiol. 2014;64:1929-49.

13. Penalva, RA, Marçal, OH, Luis, CLC, Gilson, SF, Ana MTL. Lipid profile and severity of atherosclerotic disease in acute coronary syndrome (Perfil lipídico e intensidade de doença aterosclerótica na síndrome coronariana aguda). Arquivos Brasileiros de Cardiologia. 2008;90:24-29.

14. Zand Parsa AF, Ziai H HL. The impact of cardiovascular risk factors on the site and the extent of coronary artery disease. Cardiovasc. Cardiovasc J Afr. 2012;23:197-199.

15. Veeranna V, Pradhan J, Niraj A. Traditional Cardiovascular Risk Factors and Severity of Angiographic Coronary Artery Disease in the Elderly. Preventive Cardiology. 2010;135-140.

16. Roffi M, Angiolillo DJ KA. Current concepts on coronary revascularization in diabetic patients. European Heart Journal 2011;32:2748-57.

17. Iijima R, Ndrepepa G, Kujath $\mathrm{V}$ et al. A pan-coronary artery angiographic study of the association between diabetes mellitus and progression or regression of coronary atherosclerosis. Heart Vessel. 2017;32:376-84.

18. Zheng Q, Jiang J, Huo Y, et al. Genetic predisposition to type 2 diabetes is associated with severity of coronary artery disease in patients with acute coronary syndromes. Cardiovas Diabetol. 2019;18:1-11.

19. Pollock S, Abbott RD. A Model to Predict Multivessel Coronary Artery Disease from the Exercise Thallium201 Stress Test. The American Journal of Medicine. 1991;90:345-352.

20. Heart of IJC, Chiha J, Mitchell P, et al. Gender differences in severity and extent of coronary artery disease. IJCHA. 2015;8:161-166.

21. Nakazato R, Arsanjani R, Achenbach S, et al. Age-related risk of major adverse cardiac event risk and coronary artery disease extent and severity by coronary CT angiography: results from 15187 patients from the International Multisite CONFIRM Study. Eur Heart J. 2014;15:586-594.

22. Monahan KD, Feehan RP, Sinoway LI, et al. Contribution of sympathetic activation to coronary vasodilatation during the cold pressor test in healthy men: effect of aging. J Physiol. 2013;11:2937-2947.

23. Zieman SJ, Kass DA, Hopkins J, et al. Advanced Glycation End Product Cross-Linking: Pathophysiologic Role and Therapeutic Target in. Drugs. 2004;64:459-70

24. Astrand H, Sta J, Karlsson J, et al. In vivo estimation of the contributions of elastin and collagen to the mechanical properties in the human abdominal aorta: effects of age and sex. J Physiol. 2011;176-187.

25. Wang JC, Bennett M. Aging and Atherosclerosis Mechanisms, Functional Consequences, and Potential Therapeutics for Cellular Senescence. Circ Res. 2012;111:245-259.

26. Kim CH, Koo B, Lee JM, et al. Influence of Sex on Relationship Between Total Anatomical and. Am Hear Assoc. 2019;8:1-9.

27. Hajar R. Risk Factors for Coronary Artery Disease: Historical Perspectives. Hear Views. 2017;18:109-114.

28. Guo YH, Zhang WJ, Zhou YJ, Zhao D, Zhou ZM ZH. Study of the relationship between cardiovascular risk factors and severity of coronary artery disease in patients under coronary angiography (冠状动脉造影患者心血管病危险因素 与冠状动脉病变程度的相䏌性分析). Zhonghua Xin Xue Guan Bing Za Zhi. 2005;33:415-8.

29. Lackland D. Heart Disease and Stroke Statistics - 2017 Update A Report From the American Heart Association. 2017;135:146-603.

30. Aronson D, Edelman ER. Coronary Artery Disease and Diabetes Mellitus. Cardiol Clin. 2014;32:439-455. 